Ouwehand C,de Ridder DT, Bensing, J.

A review of successful aging models: Proposing proactive coping as an important additional strategy.

Clinical Psychology Review, 2007,

\begin{tabular}{|l|l|}
\hline Postprint Version & 1.0 \\
\hline Journal website & $\underline{\text { http://www.sciencedirect.com/science?_ob=ArticleURL\&_udi=B6VB8- }}$ \\
& $\begin{array}{l}\text { 4MWPSMM- } \\
\text { 2\&_user=1421770\&_coverDate=01\%2F24\%2F2007\&_rdoc=1\&_fmt=\&_orig=s } \\
\text { earch\&_sort=d\&view=c\&_acct=C000052679\&_version=1\&_urlVersion=0\&_us } \\
\text { erid=1421770\&md5=6bc937d659f0753e53b04258432a6d34 }\end{array}$ \\
\hline Pubmed link & $\begin{array}{l}\text { http://www.ncbi.nlm.nih.gov/entrez/query.fcgi?db=pubmed\&cmd=Retrieve\&dop } \\
\text { t=AbstractPlus\&list_uids=17328997\&itool=iconabstr\&query_hl=2\&itool=pubm } \\
\text { ed_docsum }\end{array}$ \\
\hline DOI & $\underline{\text { doi:10.1016/j.cpr.2006.11.003 }}$ \\
\hline
\end{tabular}

This is a NIVEL certified Post Print, more info at http://www.nivel.eu

\title{
A review of successful aging models: Proposing proactive coping as an important additional strategy
}

\author{
CAROLIJn OUWEHAND, A, DENISE T.D. DE RIDDERA AND JOZIEN M. BENSINGA
}

aUtrecht University, Utrecht, The Netherlands

\begin{abstract}
Methods: We installed the CDSS in 118 practices [159 general practitioners (GPs)] throughout The Netherlands and calculated the costs of the intervention in this group. During a period of 6 months before and 6 months after installation of the CDSS, the testorder

Successful aging is an important concept, and one that has been the subject of much research. During the last 15 years, the emphasis of this research has shifted from formulating criteria for successful aging to describing the processes involved in successful aging. The main purpose of the present article is to review psychological models of successful aging. The model of Selective Optimization with Compensation (SOC-model) proves to be one of the leading models in this field. Although evidence about its value is accumulating, we argue that this model mainly focuses on how people react to losses and that proactive coping aimed at preventing potential threats to goals may also be a valuable strategy. We propose that proactive coping may be important for successful aging, since it results in a prolonged availability of resources for optimization and compensation processes and a delay in disengagement from important goals.
\end{abstract}

\section{INTRODUCTION}

Research has demonstrated that, despite the difficult and often inevitable losses that result from aging, many older people maintain a subjective feeling of well-being (e.g., Diener and Suh, 1997, Kunzman et al., 2000 and Smith et al., 1999). P. Baltes and M. Baltes (1990) were among the first gerontologists to state that aging might be best conceptualized as a changing balance between gains and losses. They also argued that older individuals may be able to compensate for such losses and remain satisfied with their lives. The concept of successful aging refers to the resilience of people who succeed in achieving a positive balance between gains and losses during aging (Baltes \& Baltes, 
Ouwehand C,de Ridder DT, Bensing, J.

A review of successful aging models: Proposing proactive coping as an important additional strategy. Clinical Psychology Review, 2007,

1990). As such, the elderly are not just coping with decline; they continue to actively develop themselves on numerous fronts.

During recent decades, literature on the subject has expanded, and now encompasses both theoretical considerations and empirical studies on development and growth in later life, the various resources and other factors which contribute to this process and, finally, the outcomes of successful aging. The main purpose of this article is to review current psychological models of successful aging. In particularly, we will review theoretical articles published in scientific journals and books in English from 1945 to 2005, which describe psychological models of successful aging that explain how older individuals carry on striving for their personal goals despite facing an increasing number of obstacles, in other words, how they continue to engage in self-regulation processes in older age.

In the first part of the article, these models of successful aging are described and discussed. We will argue that the researchers who developed them acknowledge losses as an inevitable part of the aging process, but suggest that the older individual is able to continue to generate positive outcomes. One of the key elements of these models is that people create environments, which make success possible while effectively dealing with losses due to aging. Striking is that the models have primarily concentrated on the strategies involved in effectively reacting to these losses, but unfortunately the review of empirical studies will demonstrate that these are also the strategies that tend to decline in older age as a result of increasing losses associated with aging. In the second part of the article, we will therefore suggest that anticipating negative changes may also be a very important and adaptive strategy in the process of successful aging, since handling losses at an early stage consumes less important resources. An interesting new perspective in the discussion about how people cope with changes and stressful events has been put forward by Aspinwall and Taylor (1997) who introduced the concept of proactive coping, which refers to the efforts people may make to prevent potential losses and other stressors from occurring or to minimize their consequences. The second aim of the article is to examine to what extent proactive coping may also be a valuable strategy for successful aging.

\section{SUCCESSFUL AGING MODELS}

\subsection{Criteria of successful aging}

Emphasis has not always been on describing the processes of successful aging. Early research in the field focused mainly on formulating criteria, which would be useful in defining successful aging. The well-known disengagement theory (Cumming \& Henry, 1961) regarded successful aging as the desire and ability of older people to disengage from active life in order to prepare themselves for death whereas the activity theory (Havighurst, 1961 and Havighurst, 1963) suggested that successful aging might be interpreted as continued adherence to the activities and attitudes of middle age and the substitution of roles, lost by changes associated with aging, in order to maintain a positive sense of oneself. Since both theories could not account for the heterogeneity found in older people, Havighurst (1963) started to define successful aging as having inner feelings of happiness and satisfaction with one's present and past life.

Ryff (1989) proposed a new set of criteria that not only emphasizes satisfaction with one's life, but that also explicitly refers to growth and progress in older age. Her definition included six dimensions of positive functioning: self-acceptance, positive relations with others, autonomy, control over one's environment, purpose in life, and personal growth. As such, one of the core ideas of successful aging at the present time, namely the idea that aging is a developmental process in which growth is still possible, was first described by Ryff (1989).

Another set of criteria was presented by Rowe and Kahn, 1987 and Rowe and Kahn, 1997, which have led to a remarkable boost in empirical studies examining the factors responsible for, for example, good health and high functioning (see the MacArthur Studies of Successful Aging). Rowe and Kahn, 1987 and Rowe and Kahn, 1997 suggested three main, partly interdependent elements of successful aging. Firstly, people have to avoid disease and disease-related disability by, for example, adopting a healthier lifestyle. The second element involves the maintenance of high cognitive and physical functional capacity, which creates potential for the final element, namely the prolongation of active engagement with life.

This definition of successful aging has not been free from criticism. The criteria are regarded as fixed end points rather than personal goals that individuals strive for throughout their life span (Pearlin \& 
Ouwehand C,de Ridder DT, Bensing, J.

A review of successful aging models: Proposing proactive coping as an important additional strategy. Clinical Psychology Review, 2007,

McKean Skaff, 1996); it describes those who have aged successfully rather than defining the process. In addition, gerontologists pointed out that, as a result of these fixed criteria, the model does not consider the many possible patterns of successful aging (Baltes and Carstensen, 1996 and Scheidt and Humpherys, 1999). Finally, the criteria proposed are viewed as normative and influenced by Western societies' ideals (Tornstam, 1992); they are culturally and historically specific. It has even been suggested that the model's assumptions and consequences may be potentially damaging for several subgroups of older people (Holstein \& Minkler, 2003).

\subsection{Processes involved in successful aging}

During the last 15 years, emphasis has shifted from formulating criteria towards outlining the processes involved in successful aging. Models have described the strategies people may employ to manage the many difficulties associated with aging in order to, for example, maintain or increase wellbeing (Kahana \& Kahana, 1996), or to continue achieving personal goals (e.g., Baltes \& Baltes, 1990), which in turn may promote subjective well-being (Brunstein, 1993, Diener et al., 1999 and Rapkin and Fisher, 1992).

One of the leading models of successful aging is the life-span model of Selective Optimization with Compensation model (SOC-model) developed by P. Baltes and M. Baltes (1990), which states that aging may be best characterized as a heterogeneous process with many different pathways and (successful) outcomes. The SOC-model's authors (Baltes \& Baltes, 1990) were therefore among the first to describe the processes of successful aging instead of solely defining the end points.

From the viewpoint of the SOC-model, people select life domains that are important to them, optimize the resources and aids that facilitate success in these domains, and compensate for losses in these domains in order to adapt to biological, psychological, and socio-economic changes throughout their lives and to create an environment for lifelong successful development. Since stressors, such as declining health, may multiply whereas resources decrease in later life, selection, optimization and compensation processes become increasingly important during aging to maintain a positive balance between gains and losses (Baltes, 1997, Baltes and Carstensen, 1996, Freund and Baltes, 2000, Freund et al., 1999 and Marsiske et al., 1995).

The SOC processes can occur at a conscious or unconscious level and in an active or passive way (Baltes et al., 1999 and Freund and Baltes, 2000) and are aimed at maximizing gains and minimizing losses while striving for personal goals (Freund et al., 1999). SOC is considered a universal mechanism, but its expression very much depends on the individual and his or her environment (Baltes, 2004), since personal goals vary from person to person, as well as according to culture and period (Baltes and Carstensen, 1996 and Marsiske et al., 1995). The SOC definition of successful aging, therefore, allows for non-normative, individual trajectories of successful development in older age.

This is contrary to the idea of Steverink, Lindenberg, and Ormel (1998) who argued that a model of successful aging should include what goals people must achieve in order to identify success objectively. Based on the social production function theory, they argue that physical well-being and social well-being are the two universal goals. Realization of these two goals depends on the achievement of first-order, instrumental goals: to attain physical well-being, comfort and stimulation are needed while affection, behavioral confirmation, and status are necessary in order to achieve social well-being (Steverink et al., 1998). Their model leaves some room for more individual goals in order to attain the instrumental goals. Nevertheless, the question remains as to what extent the proposed higher level goals, particularly the instrumental goals, are universal and not influenced by norms.

In order for the model of selective optimization with compensation to be further operationalized, it needs to be combined with domain-specific theories (Freund and Baltes, 2002 and Marsiske et al., 1995) in order to identify the content of the SOC strategies and the outcomes to which the SOC strategies are directed (Freund et al., 1999). For example, the way in which SOC may contribute to cognitive functioning and intelligence has been discussed (e.g., Baltes, 1993 and Baltes et al., 1999). In addition, the SOC-model has been elaborated using the lifespan theory of primary and secondary control (see e.g., Heckhausen and Schulz, 1993, Heckhausen and Schulz, 1995 and Schulz and Heckhausen, 1996). In this article, we will highlight the embedding of the SOC-model in an actiontheoretical framework, which explains how the employment of SOC may be useful for the attainment of personal goals (Freund and Baltes, 2000 and Freund and Baltes, 2002). 
Since resources are limited, people cannot pursue every goal in every life domain; choosing between goals, developing these goals in a coherent hierarchy and committing oneself to them is crucial for development. Elective selection is the concept that refers to this idea and operates in the absence of losses (Freund and Baltes, 2000, Freund and Baltes, 2002 and Freund and Riediger, 2001). In order to pursue and achieve the personal goal that have been set, sufficient and proper resources are necessary as is the efficient utilization of these resources. Optimization is the process which is directed at acquiring the needed resources: developing new skills, modeling other successful one's, using one's energy to pursue personal goals are all examples of optimization. When resources decline or are lost (as in aging) compensation strategies become necessary to avoid a reduction in self-regulation with regard to goals (Freund and Baltes, 2000, Freund and Baltes, 2002 and Freund and Riediger, 2001). An individual may compensate by using technology, such as a hearing aid or a wheelchair, but also by increasing his or her efforts or by learning new skills. Both optimization and compensation processes not only generate resources, but also depend on the availability of resources (Freund \& Baltes, 2000). When in later life losses begin to outweigh gains, loss-based selection becomes more prominent. As a result of these losses, individuals start to focus on their most important goals, reconstruct their goal hierarchy, disengage from original goals and set new goals (Freund \& Baltes, 2002).

The importance of accepting losses and disengaging from goals that can no longer be pursued in old age has also been emphasized by other researchers, such as Heckhausen and Schulz (1995), Schulz and Heckhausen (1996), who have developed a life span model of primary and secondary control. According to this model, people use secondary control strategies directed at changing the evaluation of blocked goals, which results in disengagement. Brandtstädter and colleagues (e.g., Brandtstädter and Greve, 1994, Brandtstädter and Rothermund, 1994 and Brandtstädter and Rothermund, 2002) have presented similar ideas with their model of assimilative and accommodative processes. Although assimilative strategies, that is, actively changing the environment to fit personal goals, are preferable as long as it is possible to invest resources, people may have to switch to accommodative strategies when resources for compensation diminish in order to remain satisfied with themselves and their life (Brandtstädter \& Rothermund, 2002). Contrary to the SOC-model, Brandtstädter and Rothermund (2002) propose that disengaging from blocked goals is an unintentional and gradual process, particularly in the case of goals that are central to an individual. In any case, disengagement is often necessary in order to regulate negative emotions in later life, to remain satisfied with one's performance (Rothermund \& Brandtstädter, 2003a) and to avoid depression in later life (Rothermund \& Brandtstädter, 2003b). In other words, accommodative flexibility may be a valuable part of successful aging. Interestingly, Wrosch, Scheier, Miller, Schulz, and Carver (2003) found that disengagement from unattainable goals was related to higher subjective well-being in older adults (aged 55 to 89), but only when these individuals had the tendency to find new goals that were meaningful to them, a process they termed goal reengagement (see e.g., Wrosch, Scheier, Carver, \& Schulz, 2003).

To summarize, the SOC-model outlines the processes through which older people actively cope with the many changes associated with aging. Successful aging is not about not having to face any losses, but about dealing successfully with these negative changes. Furthermore, the SOC-model stresses the significance of creating environments in which success is possible, by choosing between life domains and prioritizing goals. In this sense, this model is very promising in explaining successful aging. Next, we will systematically review whether empirical studies provide evidence for the SOC-model's predictive and explanatory value with regard to successful aging.

\section{EMPIRICAL EVIDENCE}

\subsection{Systematic search for empirical articles regarding SOC}

To conduct a review of the empirical studies regarding SOC and successful aging, we completed computer searches in PsycLit and PsycInfo as well as manual searches by tracking citations in selected articles. For the computer search, we used the following key words: selective optimization (with) compensation, SOC, successful aging, adaptation. The search was limited to empirical studies that have been published in scientific journals in English from 1990 to 2005. Studies were selected when: (a) a sample of middle-aged and/or older adults (45 years and older) was included; (b) SOC-strategies were assessed either by self-report measures or measures of behavioral indicators; and (c) quantitative 
Ouwehand C,de Ridder DT, Bensing, J.

A review of successful aging models: Proposing proactive coping as an important additional strategy. Clinical Psychology Review, 2007,

results were presented. A total of nine relevant studies was identified (Abraham and Hansson, 1995, Chou and Chi, 2002, Freund and Baltes, 1998, Freund and Baltes, 1999, Freund and Baltes, 2002, Gignac et al., 2002, Lang and Carstensen, 1994, Lang et al., 2002 and Li et al., 2001).

\subsection{SOC and successful aging}

An important issue is whether the SOC-model is useful in predicting and explaining outcomes. Therefore, we will first review whether there is empirical evidence for the suggested contribution of SOC to successful aging. Freund and Baltes, 1998 and Freund and Baltes, 1999 conducted a crosssectional study of 200 older people between 72 and 103 years old who reported their SOC strategies by filling out the SOC-questionnaire, which is a self-report measure for SOC as strategies for life management (for a detailed description of the SOC-questionnaire and its validity and reliability, see Freund \& Baltes, 2002). Results showed that a greater amount of SOC was moderately to highly and positively associated with satisfaction with age, positive emotions and absence of social and emotional loneliness, even after controlling for other variables, such as age, control beliefs, subjective health and personality. Although all SOC strategies were involved, optimization and compensation made the greatest contribution to well-being (Freund and Baltes, 1998 and Freund and Baltes, 1999). Two other cross-sectional studies by Freund and P. Baltes (2002) with 218 and 181 individuals respectively replicated these results; moderate, positive relationships were found between the self-reported use of SOC strategies and positive emotions and subjective well-being. Associations remained after controlling for other variables, such as personality, and were strongest for optimization followed by compensation and loss-based selection.

SOC does not only contribute to successful aging in general, but also to successfully adjusting to specific, difficult situations. In a laboratory study with 40 older people between 60 and 75 years old, $\mathrm{Li}$ and colleagues (2001) found that the elderly select the activity most important to them (walking and keeping balance) when they have to perform two tasks at the same time, namely memorize words while they had to walk along a narrow track. Moreover, they make use of compensatory means that help them performing the chosen task. In other words, when confronted with decreasing abilities, these older individuals maintain a prior performance level by selecting what is most important and using compensatory strategies ( $\mathrm{Li}$ et al., 2001).

In order to examine whether the SOC-model has the potential to explain how older adults adapt to disability, Gignac and others (2002) conducted a cross-sectional study that examined behavioral adaptations of 248 adults aged 55 years and older with osteoarthritis, a chronic and incurable physical illness. They found that behavioral strategies, such as the use of supportive devices, indicating compensation are most often employed by people suffering from long-term disability, particularly those individuals who had undergo surgery or are more disabled. Optimization, measured by behavioral activities, such as planning activities and walking to avoid pain, is the next most frequently used strategy.

In addition, in a cross-sectional study with 421 people aged 60 years and older, Chou and Chi (2002) examined whether self-reported SOC moderated the relationship between financial hardship and lifesatisfaction. It appeared that optimization in particular, but also selection were significant moderators in this relationship after controlling for various socio-demographic variables, such as age, gender and education. In other words, the association between financial strain and life-satisfaction is lower when elderly people use more selection and optimization strategies.

Finally, Abraham and Hansson (1995) demonstrated in a cross-sectional study with 224 employed adults aged 40 to 69 that the use of SOC strategies in order to maintain job competencies becomes increasingly important during aging. The positive correlation between selection and self-reported ability and performance maintenance was largest for the oldest employees whereas the positive associations between optimization and compensation with self-reported goal attainment also increased with age (Abraham \& Hansson, 1995). Thus, although all adults take advantage of engaging in SOC, this is especially true for the older individuals.

A limitation of these studies is that they are cross-sectional of nature, which makes it impossible to draw a final conclusion about causality. Longitudinal studies are needed to further understand the causal relationship between SOC and successful aging. Lang and colleagues (2002) conducted such a longitudinal study with 195 adults aged 70 to 103. They examined whether cross-sectional indicators of SOC predicted survival 4 years later. Significant differences were found between survivors and 
Ouwehand C,de Ridder DT, Bensing, J.

A review of successful aging models: Proposing proactive coping as an important additional strategy. Clinical Psychology Review, 2007,

non-survivors with respect to activity, diversity of leisure activities, and variability of time investments across activities. Survivors show more selection regarding leisure activities indicated by directing their energy at a lesser range of activities and more optimization indicated by investing more time in the activities they selected (Lang et al., 2002).

To conclude, empirical studies suggest that the SOC-model is a promising model of successful aging. They have shown the potential usefulness of the model in explaining the differences in middle-aged and older people with regard to success and in predicting successful aging in general, as well as successful adaptation to difficult changes related to aging. Although challenges remain for future research, a promising start has been made.

\subsection{Decrease in the use of SOC by the elderly}

One of the most significant results of the studies described above is the finding that compensation and optimization in particular are associated with successful aging. However, the following empirical studies show that these are also the strategies that are most likely to decline in old age as a result of increasing losses, especially in people who have few resources left.

In a cross-sectional study with 181 adults aged 18 years and older, Freund and P. Baltes (2002) found that self-reported SOC strategies first increase from young to middle adulthood and subsequently decline after the age of 67 . These findings corroborate with the results of another cross-sectional study with 200 older adults aged 72 to 103, which demonstrated that the age-related decline of optimization and compensation continues in advanced old age (Freund and Baltes, 1998 and Freund and Baltes, 1999).

Interestingly, the cross-sectional study by Freund and P. Baltes (2002) also showed that elective selection is the only SOC-strategy that continues to increase moderately in older adulthood. In addition, cross-sectional research on the size and quality of 156 older (aged 70 to 104) people's social networks demonstrated that the number of social partners decreases with age whereas the number of very close relationships remains the same (Lang \& Carstensen, 1994). Freund and P. Baltes (2002) have suggested that the positive relationship between age and elective selection might be explained by the idea that middle-aged and older adults become aware of their specific pathway in life and, therefore, focus more and more on their selected goals. Nevertheless, whether it is possible to properly disentangle elective selection and loss-based selection in older age is debatable, particularly when results are based on self-report measures. People may report that they always focus their energy on a few important goals, but may not always be able to recognize this as loss-based selection, particularly when disengagement from goals occurs somewhat automatically and rather gradually. Thus, the basis of this continued selection process might also be explained by the fact that people are no longer capable of pursuing all their goals due to the aging process. Further research is needed to examine this more closely.

A problem is that the age-related differences in SOC found in these studies can be explained by a chronological age effect, a cohort effect, or a combination of both effects (Freund and Baltes, 2002 and Schaie and Baltes, 1975). Future, longitudinal studies are needed to unravel the precise contribution of these effects. Rothermund and Brandtstädter (2003a) already found in a 4-year longitudinal study with 762 older adults between 58 and 81 years old that compensation accumulates until the age of 70, after which it sharply reduces as a consequence of a decline in the availability of resources.

It has been suggested that the demonstrated decline in most SOC strategies in older adulthood is probably the result of an age-related reduction of resources, which makes it difficult to engage in optimization and compensation, since these processes themselves expend a lot of resources and efforts (Freund \& Baltes, 2002). Cross-sectional research in a sample of 516 individuals showed that older people aged 70 to 102 who are still rich in resources are less susceptible to a decrease in everyday functioning than resource-poor people (Baltes \& Lang, 1997). Whether this is due to a greater employment of SOC strategies was examined in a longitudinal study which demonstrated that, compared with older adults with a small amount of resources, people between 70 and 103 years old with many resources use more compensation and optimization strategies (Lang et al., 2002). These moderate to large differences remained after controlling for age. 
Ouwehand C,de Ridder DT, Bensing, J.

A review of successful aging models: Proposing proactive coping as an important additional strategy. Clinical Psychology Review, 2007,

\subsection{Conclusion}

The review of empirical studies examining SOC strategies suggests that the SOC-model is a potentially useful model of successful aging. Compensation and optimization in particular are important strategies for successful aging. Paradoxically, the review also shows that these are the strategies most likely to become increasingly difficult to use as a result of age-related losses in resources, which are necessary to have in order to be able to engage in compensation and optimization. Persisting with optimization and compensation may then consume so many resources that other important activities can no longer be carried out (Freund \& Baltes, 2002) and disengagement from goals or loss-based selection becomes inevitable. We argue that people may be capable of foreseeing future problems and losses and take appropriate preventive actions before these stressors fully reveal themselves; in other words, they are able to engage in proactive coping (Aspinwall, 1997 and Aspinwall and Taylor, 1997). Preventing potential stressors from emerging may result in an extended availability of resources for optimization and compensation. This means that personal goals may be pursued and attained for longer, which ultimately contributes to subjective well-being (Brunstein, 1993, Diener et al., 1999 and Rapkin and Fisher, 1992). In other words, we propose that proactive coping may be a valuable strategy for successful aging.

The SOC-model has mainly described the processes through which people react to the multiple changes associated with aging that may threaten personal goals. Although it is to some extent proactive, since elective selection and optimization require future oriented thinking, the SOC-model did not explicitly pay attention to the strategies people may employ in advance of a potential loss in resources in order to avoid it. In the remaining part of this article, we will examine the possible value of proactive coping for the SOC-model of successful aging.

\section{PROACTIVE COPING}

\subsection{Proactive coping and successful aging}

Some researchers have acknowledged the important role of preventive activities for successful aging, in addition to reacting effectively to stressful changes. As early in the history of gerontology as 1951, Paulus (1951, p. 401) suggested that "successful aging must be prepared long in advance; a happy old age is the criterion and reward of a well conducted life". More recently, in their model of preventive and corrective proactivity, Kahana and Kahana, 1996 and Kahana and Kahana, 2001 described strategies to effectively deal with the unique stressors associated with aging in order to avoid negative outcomes. These strategies do not only include corrective actions to cope with stressors once they have occurred, but also several preventive actions made prior to the stressors' occurrence in order to delay them or minimize their number (Kahana and Kahana, 1996 and Kahana and Kahana, 2001). These preventive behaviors include health promotion to reduce the risk of declining health, planning for the future, and helping others in order to enhance the range of social resources that may be drawn upon in difficult times. This is partly in line with Rowe and Kahn (1997) who suggested that avoiding disease and maintaining high physical functioning is an important part of successful aging. Only one empirical study has used the Kahanas' model as a theoretical basis and has examined the role of preventive strategies for success. Results from a longitudinal study showed that the quality of life of 357 older adults aged 72 to 98 who engaged in several preventive health behaviors, such as exercising and giving up smoking, was enhanced after 8 years (Kahana et al., 2002).

Despite the fact that E. Kahana and B. Kahana (1996) identified the three preventive activities (health promotion, planning, and helping others) as the behaviors most often employed by older adults, it is debatable whether these are the only preventive strategies people may engage in. We propose that proactive coping may vary among and within individuals and will depend on an individual's personal goals, the specific potential stressors people may encounter while aging and to what extent they experience these stressors as a threat to their goals. While it is likely that every individual will pass through the same stages of proactive coping, they may differ in the behavioral efforts or cognitive activities they ultimately undertake, which are the results of this psychological process, in order to handle the same type of potential stressor. Moreover, proactive coping efforts may also differ within an individual, as different types of stressors often require different types of actions.

Following Aspinwall and Taylor (1997), we define proactive coping as the strategies people apply to prevent future stressors or to minimize their effects. Proactive coping is a psychological process, 
Ouwehand C,de Ridder DT, Bensing, J.

A review of successful aging models: Proposing proactive coping as an important additional strategy. Clinical Psychology Review, 2007,

which can be divided in five stages. A first requirement for engaging in proactive coping is having enough resources, which may be accumulated during life (stage 1), in order to build up resistance and to be prepared as much as possible (Aspinwall, 1997). To identify a potential stressor, the environment has to be screened for danger (stage 2) and cues indicating a potential stressor have to be recognized and appraised as a threat that requires action (stage 3). A focus group study with 47 people aged 50 to 70 indeed demonstrated that people need to experience at least a slight feeling of threat in order to direct their attention to a potential stressor and to become motivated to engage in proactive coping (Ouwehand, De Ridder, \& Bensing, 2001).

Initial coping efforts (stage 4) include both behavioral actions, such as seeking more information about the stressor, and cognitive strategies, such as planning, aimed at preventing or minimizing the stressor. Aspinwall and Taylor (1997) propose that proactive coping efforts are active rather than avoidant, because avoidance of thinking about the stressor does not contribute to controlling the problem. Feedback (stage 5) is a necessary final stage in proactive coping, since it provides information about the development of the potential stressor and the results of one's coping efforts. Important skills in proactive coping include planning, regulation of negative emotions invoked by thinking about a stressor, and mental simulation (Aspinwall, 1997 and Aspinwall and Taylor, 1997).

An advantage of proactive coping is that stressors are encountered in an early stage; its impact may be lowered when the stressors fully emerge (Aspinwall \& Taylor, 1997). Consequently, the stressor will consume relatively less resources (Aspinwall, 1997), which means that these resources remain available for other activities. Furthermore, older people often have to deal with stressors that imply a loss of resources themselves. For example, a decrease in health is not only a stressful change that depletes resources; it is also a decline in one of the most important resources for goal pursuit and other actions. In short, preventing potential stressors associated with aging may help to preserve resources, which may be used to continue engaging in optimization and compensation for as long as possible. This is important, because the empirical studies described above have shown that these strategies are significantly associated with successful aging. We propose that disengagement from important goals, therefore, may be postponed by using proactive coping. Some problems, however, may be insoluble. Attempting to prevent these stressors may unnecessarily drain many valuable resources (Aspinwall \& Taylor, 1997). However, we suggest that screening the environment and thinking about these future insoluble stressors, in other words engaging in proactive coping, may also be adaptive in this situation, even if it implies early disengagement from goals that are threatened by these types of stressors.

\subsection{Empirical studies}

Little empirical research has been conducted to examine whether older people are able to engage in proactive coping and whether this actually contributes to SOC and successful aging. Until now, empirical studies have shown that older people do not avoid problems or passively react to them; they are capable of using as many effective problem-focused coping strategies as their younger counterparts (Aldwin, 1991 and Aldwin et al., 1996). Furthermore, Freitas, Liberman, Salovey, and Higgins (2002) have demonstrated that people with a "prevention focus" (Higgins, 1997), either chronic or induced by a specific situation, initiate action earlier than people who only think about desired outcomes. A recent field experiment with 123 adults aged 50 to 70 (Ouwehand, De Ridder, \& Bensing, in press) showed that proactive coping does not only depend on personal features, but may also be highly variable within individuals. Situational factors, such as type of stressor and appraised amount of control over the stressor, determine the use of proactive coping strategies to a greater extent than individual characteristics.

Nevertheless, people may not always have the opportunity to act in advance. Recent cross-sectional research by the authors has examined the hypothesis that current stress, either due to general living conditions or specific stressors, hampers proactive coping (Aspinwall and Taylor, 1997, Ouwehand, 2005 and Ouwehand et al., 2004). Stress may drain valuable resources, such as attention, that can no longer be invested in complex tasks, such as proactive coping, which requires integration of information from different resources (Chajut \& Algom, 2003). In a large cross-sectional study with more than 3000 people between 50 and 70 years old, we found that poor physical health is negatively associated with the use of proactive coping (Ouwehand, 2005). In addition, the same study demonstrated that people low in socioeconomic status (SES) tend to use less proactive coping partly due to the fact that they experience poorer health (Ouwehand et al., 2004). 
Ouwehand C,de Ridder DT, Bensing, J.

A review of successful aging models: Proposing proactive coping as an important additional strategy. Clinical Psychology Review, 2007,

Whether engaging in proactive coping contributes to successful aging has barely been examined empirically. Nevertheless, related research suggests its potential value for successful aging. For example, cross-sectional research by Prenda and Lachman (2001) showed that future-oriented planning strategies positively influence life-satisfaction in 2971 adults aged 25 to 75 . Although planning for the future declines with age, older adults between 60 and 75 years old benefit the most from planning (Prenda \& Lachman, 2001). Furthermore, the longitudinal study by E. Kahana and colleagues (2002), which has been described above, demonstrated that preventive strategies directed at enhancing one's health result in a higher quality of life of the elderly 8 years later.

\subsection{Clinical application}

An important question is whether the concept of proactive coping is not only relevant for theoretical application, but is also potentially useful for the clinical field. A recent intervention study was designed by Bode, De Ridder, and Bensing (2006), which is the first study that examined to what extent middle-aged and older people between 50 and 75 years old may be capable of learning to use proactive coping. It demonstrated that a minimal intervention program of four meetings is enough to change the 68 individuals' proactive coping competencies. Not only proved their program "In anticipation of the golden years" to be successful in learning its participants to employ proactive coping, it was also regarded by the participants as appealing and highly feasible (Bode et al., 2006).

\section{DISCUSSION}

\subsection{Future research}

Reflecting on personal goals and actively attempting to achieve them are important ingredients for successful aging, since they contribute to subjective well-being (Brunstein, 1993, Diener et al., 1999 and Rapkin and Fisher, 1992). The SOC-model, which concentrates on the strategies that enhance this self-regulation process, takes into account that successful aging may have many different pathways and successful outcomes. Some researchers suggest that even this non-normative definition of successful aging is a typical idea of "Western societies that value success in terms of individual accomplishments” (Torres, 1999, p. 37). Torres (2003) suggests that some cultures might regard acceptance of unavoidable changes as success. However, research has demonstrated that Chinese people also engage in SOC when confronted with stressful situations (e.g., Chou \& Chi, 2002) and, on the other hand, Western researchers have acknowledged the importance and inevitability of acceptance as has been outlined in this article. It would be interesting to further examine the cross-cultural value of the SOC-model and the idea of proactive coping.

One difference may be that Western cultures consider that actively changing one's environment to fit one's goals is preferable as long as it is possible to invest sufficient resources (Brandtstädter and Rothermund, 2002 and Heckhausen and Schulz, 1995). As we have argued in the present article, proactive coping strategies may be employed to prolong these processes by conserving valuable resources for optimization and compensation. Studies have just started to provide empirical evidence for proactive coping and its contribution to successful aging.

Nevertheless, many interesting questions are still unanswered at this point in time. For example, a question to be answered is whether proactive coping might have negative and unintended side effects. It may consume important resources when a potential stressor is appraised wrongly (Aspinwall \& Taylor, 1997), which may lead to accommodation strategies being triggered sooner than necessary. Other negative consequences include rumination and high vigilance (Aspinwall \& Taylor, 1997), which might have the opposite effect than intended. Intervention studies should therefore take into account that learning to employ proactive coping strategies may also have damaging effects for some people.

A final challenge for future research is to examine how models of successful aging may be useful for empirical research. The operationalization of processes is often difficult. For example, the concept of proactive coping embraces a process over time, which yet alone consists of many different elements, both behavioral strategies and cognitive activities, that cannot be determined in one single measurement. It would be useful to focus research on the smaller parts of the process using measurement instruments that do not depend on self-report. Self-report measures frequently include prepared response items that more often assess attitudes and dispositional acting styles instead of 
Ouwehand C,de Ridder DT, Bensing, J.

A review of successful aging models: Proposing proactive coping as an important additional strategy. Clinical Psychology Review, 2007,

behavior that may change over time and may depend on the situation. Other problems include the fact that individuals are not able to report their efforts correctly (Schwartz, Neale, Marco, Shiffman, \& Stone, 1999) and tend to employ socially desirable answering (Coyne \& Gottlieb, 1996). It might therefore be productive for future research to consider developing new measures.

\subsection{Conclusion}

During the last decade, as researchers started to acknowledge that aging is a heterogeneous process with many different pathways that may all result in the maintenance of life satisfaction in advanced age, emphasis has switched from specifying criteria of successful aging to outlining the strategies involved in this process. The SOC-model appears to be an important model with the potential to explain and predict successful aging in different types of people and situations. Although SOC strategies contribute to successful aging, it becomes increasingly difficult to engage in these activities due to the fact that resources decline in old age. In the present article, we have argued that proactive coping, that is, attempting to prevent potential stressors that are the cause of this decrease in resources, may be a valuable strategy as well, albeit one that has hardly been addressed in models of successful aging. By anticipating potential stressors at an early stage, proactive coping may conserve resources important for optimization and compensation and, therefore, postpone disengagement from valuable personal goals, the attainment of which contributes to subjective well-being.

\section{REFERENCES}

Abraham and Hansson, 1995 J.D. Abraham and R.O. Hansson, Successful aging at work: An applied study of selection, optimization, and compensation through impression management, Journals of Gerontology. Series B, Psychological Sciences and Social Sciences 50B (1995), pp. P94-P103. View Record in Scopus | Cited By in Scopus

Aldwin, 1991 C.M. Aldwin, Does age affect the stress and coping process? Implications of age differences in perceived control, Journals of Gerontology. Series B, Psychological Sciences and Social Sciences 46B (1991), pp. P174-P180. View Record in Scopus | Cited By in Scopus

Aldwin et al., 1996 C.M. Aldwin, K.J. Sutton, G. Chiara and A. Spiro, Age differences in stress, coping, and appraisal: Findings from the Normative Aging Study, Journals of Gerontology. Series B, Psychological Sciences and Social Sciences 51B (1996), pp. P179-P188. View Record in Scopus | Cited By in Scopus

Aspinwall, 1997 L.G. Aspinwall, Where planning meets coping: Proactive coping and the detection and management of potential stressors. In: S.L. Friedman and E.K. Scholnick, Editors, The developmental psychology of planning: Why, how, and when do we plan?, Lawrence Erlbaum Associates Publishers, London (1997), pp. 285-320.

Aspinwall and Taylor, 1997 L.G. Aspinwall and S.E. Taylor, A stitch in time: Self-regulation and proactive coping, Psychological Bulletin 121 (1997), pp. 417-436. Abstract | Abstract + References | PDF (2774 K) | Full Text via CrossRef | View Record in Scopus | Cited By in Scopus

Baltes, 1993 P.B. Baltes, The aging mind: Potential and limits, The Gerontologist 33 (1993), pp. 580594. View Record in Scopus | Cited By in Scopus

Baltes, 1997 P.B. Baltes, On the incomplete architecture of human ontogeny, American Psychologist 52 (1997), pp. 366-380. Abstract | Abstract + References | PDF (2272 K) | Full Text via CrossRef | View Record in Scopus | Cited By in Scopus

Baltes, 2004 Baltes, P. B. (2004). A general model of successful (proactive) aging: Selective optimization with compensation. Paper presented at the 57th Annual Scientific Meeting of the Gerontological Society of America, Washington.

Baltes and Baltes, 1990 P.B. Baltes and M.M. Baltes, Psychological perspectives on successful aging: The model of selective optimization with compensation. In: P.B. Baltes and M.M. Baltes, Editors, Successful aging: Perspectives from the behavioral sciences, Cambridge University Press, New York (1990), pp. 1-34.

Baltes and Carstensen, 1996 M.M. Baltes and L.L. Carstensen, The process of successful ageing, Ageing and Society 16 (1996), pp. 397-422. View Record in Scopus | Cited By in Scopus

Baltes and Lang, 1997 M.M. Baltes and F.R. Lang, Everyday functioning and successful aging: The impact of resources, Psychology and Aging 12 (1997), pp. 433-443. Abstract | Abstract + References | PDF (1701 K) | Full Text via CrossRef | View Record in Scopus | Cited By in Scopus 
Ouwehand C,de Ridder DT, Bensing, J.

A review of successful aging models: Proposing proactive coping as an important additional strategy. Clinical Psychology Review, 2007,

Baltes et al., 1999 P.B. Baltes, U.M. Staudinger and U. Lindenberger, Lifespan psychology: Theory and application to intellectual functioning, Annual Review of Psychology 50 (1999), pp. 471-507.

Full Text via CrossRef | View Record in Scopus | Cited By in Scopus

Bode et al., 2006 C. Bode, D.T.D. De Ridder and J.M. Bensing, Preparing for aging: Development, feasibility and preliminary results of an educational program for midlife and older based on proactive coping theory, Patient Education and Counseling 61 (2006), pp. 272-278. SummaryPlus | Full Text + Links | PDF (156 K) | View Record in Scopus | Cited By in Scopus

Brandtstädter and Greve, 1994 J. Brandtstädter and W. Greve, The aging self: Stabilizing and protective processes, Developmental Review 14 (1994), pp. 52-80. Abstract | PDF (1611 K)

Brandtstädter and Rothermund, 1994 J. Brandtstädter and K. Rothermund, Self-percepts of control in middle and later adulthood: Buffering losses by rescaling goals, Psychology and Aging 9 (1994), pp. 265-273. Abstract | PDF (857 K) | Full Text via CrossRef | View Record in Scopus | Cited By in Scopus

Brandtstädter and Rothermund, 2002 J. Brandtstädter and K. Rothermund, The life-course dynamics of goal pursuit and goal adjustment: A two-process framework, Developmental Review 22 (2002), pp. 117-150. Abstract | Abstract + References | PDF (154 K) | View Record in Scopus | Cited By in Scopus

Brunstein, 1993 J.C. Brunstein, Personal goals and subjective well-being: A longitudinal study, Journal of Personality and Social Psychology 65 (1993), pp. 1061-1070. Abstract | PDF (996 K) | Full Text via CrossRef

Chajut and Algom, 2003 E. Chajut and D. Algom, Selective attention improves under stress: Implications for theories of social cognition, Journal of Personality and Social Psychology 85 (2003), pp. 231-248. SummaryPlus | Full Text + Links | PDF (295 K) | Full Text via CrossRef | View Record in Scopus | Cited By in Scopus

Chou and Chi, 2002 K.L. Chou and I. Chi, Financial strain and life satisfaction in Hong Kong elderly Chinese: Moderating effect of life management strategies including selection, optimization, and compensation, Aging and Mental Health 6 (2002), pp. 172-177. Full Text via CrossRef | View Record in Scopus | Cited By in Scopus

Coyne and Gottlieb, 1996 J.C. Coyne and B.H. Gottlieb, The mismeasure of coping by checklist, Journal of Personality 64 (1996), pp. 959-991. Full Text via CrossRef | View Record in Scopus | Cited By in Scopus

Cumming and Henry, 1961 E. Cumming and W.E. Henry, Growing old: The process of disengagement, Basic Books, New York (1961).

Diener and Suh, 1997 E. Diener and M.E. Suh, Subjective well-being and age: An international analysis, Annual Review of Gerontology and Geriatrics 17 (1997), pp. 304-324.

Diener et al., 1999 E. Diener, M.E. Suh, R.E. Lucas and H.L. Smith, Subjective well-being: Three decades of progress, Psychological Bulletin 125 (1999), pp. 276-302. Full Text via CrossRef | View Record in Scopus | Cited By in Scopus

Freitas et al., 2002 A.L. Freitas, N. Liberman, P. Salovey and E.T. Higgins, When to begin? Regulatory focus and initiating goal pursuit, Personality and Social Psychology Bulletin 28 (2002), pp. 121-130. Full Text via CrossRef | View Record in Scopus | Cited By in Scopus

Freund and Baltes, 1998 A.M. Freund and P.B. Baltes, Selection, optimization, and compensation as strategies of life management: Correlations with subjective indicators of successful aging,

Psychology and Aging 13 (1998), pp. 531-543. Abstract | Abstract + References | PDF (913 K) | Full Text via CrossRef | View Record in Scopus | Cited By in Scopus

Freund and Baltes, 1999 A.M. Freund and P.B. Baltes, Selection, optimization, and compensation as strategies of life management: Correction to Freund and Baltes (1998), Psychology and Aging 14 (1999), pp. 700-702. Abstract | Abstract + References | PDF (155 K) | Full Text via CrossRef | View Record in Scopus | Cited By in Scopus

Freund and Baltes, 2000 A.M. Freund and P.B. Baltes, The orchestration of selection, optimization, and compensation: An action-theretical conceptualization of a theory of developmental regulation. In: W.J. Perrig and A. Grob, Editors, Control of human behavior, mental processes, and consciousness: Essays in honor of the 60th birthday of August Flammer, Lawrence Erlbaum Associates Publishers, London (2000), pp. 35-58.

Freund and Baltes, 2002 A.M. Freund and P.B. Baltes, Life-management strategies of selection, optimization, and compensation: Measurement by self-report and construct validity, Journal of Personality and Social Psychology 82 (2002), pp. 642-662. Abstract | Abstract + References | PDF $(155 \mathrm{~K})$ | Full Text via CrossRef

Freund et al., 1999 A.M. Freund, K.Z.H. Li and P.B. Baltes, Successful development and aging: The role of selection, optimization, and compensation. In: J. Brandtstädter and R.M. Lerner, Editors, 
Ouwehand C,de Ridder DT, Bensing, J.

A review of successful aging models: Proposing proactive coping as an important additional strategy. Clinical Psychology Review, 2007,

Action and self-development: Theory and research through the life span, Sage Publications, Thousand Oaks (1999), pp. 401-434.

Freund and Riediger, 2001 A.M. Freund and M. Riediger, What I have and what I do: The role of resource loss and gain throughout life, Applied Psychology: An International Review 50 (2001), pp. 370-380.

Gignac et al., 2002 M. A.M. Gignac, C. Cott and E.M. Badley, Adaptation to disability: Applying selective optimization with compensation to the behaviors of older adults with osteoarthritis, Psychology and Aging 17 (2002), pp. 520-524. Abstract | Abstract + References | PDF (60 K) | Full Text via CrossRef | View Record in Scopus | Cited By in Scopus

Havighurst, 1961 R.J. Havighurst, Successful aging, The Gerontologist 1 (1961), pp. 8-13.

Havighurst, 1963 R.J. Havighurst, Successful aging. In: R.H. Williams, C. Tibbitts and W. Donahue, Editors, Processes of aging, Atherton Press, New York (1963), pp. 299-320.

Heckhausen and Schulz, 1993 J. Heckhausen and R. Schulz, Optimisation by selection and compensation: Balancing primary and secondary control in life span development, International Journal of Behavioural Development 16 (1993), pp. 287-303.

Heckhausen and Schulz, $1995 \mathrm{~J}$. Heckhausen and R. Schulz, A life-span theory of control, Psychological Review 102 (1995), pp. 284-304. Abstract | Abstract + References | PDF (2438 K) | Full Text via CrossRef | View Record in Scopus | Cited By in Scopus

Higgins, 1997 E.T. Higgins, Beyond pleasure and pain, American Psychologist 52 (1997), pp. 12801300. Abstract | Abstract + References | PDF (1840 K) | Full Text via CrossRef

Holstein and Minkler, 2003 M.B. Holstein and M. Minkler, Self, society, and the "new gerontology", The Gerontologist 43 (2003), pp. 787-796. View Record in Scopus | Cited By in Scopus

Kahana and Kahana, 1996 E. Kahana and B. Kahana, Conceptual and empirical advances in understanding aging well through proactive adaptation. In: V.L. Bengtson, Editor, Adulthood and aging. Research on continuities and discontinuities, Springer, New York (1996), pp. 18-40.

Kahana and Kahana, $2001 \mathrm{E}$. Kahana and B. Kahana, Successful aging among people with HIVIAIDS, Journal of Clinical Epidemiology 54 (2001), pp. S53-S56. SummaryPlus | Full Text + Links | PDF (78 K) | View Record in Scopus | Cited By in Scopus

Kahana et al., 2002 E. Kahana, R.H. Lawrence, B. Kahana, K. Kercher, A. Wisniewski and E. Stoller et al., Long-term impact of preventive proactivity on quality of life of the old-old, Psychosomatic Medicine 64 (2002), pp. 382-394. View Record in Scopus | Cited By in Scopus

Kunzman et al., 2000 U. Kunzman, T.D. Little and J. Smith, Is age-related stability of subjective wellbeing a paradox? Cross-sectional and longitudinal evidence from the Berlin Aging Study, Psychology and Aging 15 (2000), pp. 511-526.

Lang and Carstensen, 1994 F.R. Lang and L.L. Carstensen, Close emotional relationships in late life: Further support for proactive aging in the social domain, Psychology and Aging 9 (1994), pp. 315324. Abstract | PDF (6835 K) | Full Text via CrossRef | View Record in Scopus | Cited By in Scopus

Lang et al., 2002 F.R. Lang, N. Rieckmann and M.M. Baltes, Adapting to aging losses: Do resources facilitate strategies of selection, compensation, and optimization in everyday functioning?, Journals of Gerontology. Series B, Psychological Sciences and Social Sciences 57B (2002), pp. P501-P509. View Record in Scopus | Cited By in Scopus

Li et al., 2001 K.Z.H. Li, U. Lindenberger, A.M. Freund and P.B. Baltes, Walking while memorizing: Age-related differences in compensatory behavior, Psychological Science 12 (2001), pp. 230-237. View Record in Scopus | Cited By in Scopus

Marsiske et al., 1995 M. Marsiske, F.R. Lang, P.B. Baltes and M.M. Baltes, Selective optimization with compensation: Life-span perspectives on successful human development. In: R.A. Dixon and L. Bäckman, Editors, Compensating for psychological deficits and declines: Managing losses and promoting gains, Lawrence Erlbaum Associates, Publishers, New Jersey (1995), pp. 35-79.

Ouwehand, 2005 Ouwehand, C. (2005). Proactive coping and successful aging: What role do resources and strategies play in the preparation for potential goal threats associated with aging? Doctoral dissertation, Utrecht University, Utrecht, The Netherlands.

Ouwehand et al., 2001 Ouwehand, C., De Ridder, D. T. D.,Bensing, J.M. (2001). Proactive adaptation to ageing: An exploratory focus group study. Unpublished manuscript, Utrecht University.

Ouwehand et al., 2004 Ouwehand, C., De Ridder, D. T. D., \& Bensing, J.M. (2004). Looking in the future: The socioeconomic selectivity of proactive coping. Paper presented at the 57th Annual Scientific Meeting of the Gerontological Society of America, Washington.

Ouwehand et al., 2006 C. Ouwehand, D.T.D. De Ridder and J.M. Bensing, Situational aspects are more important in shaping proactive coping behaviour than individual characteristics: A vignette study among adults preparing for ageing, Psychology and Health 21 (2006), pp. 809-825. Full Text via CrossRef | View Record in Scopus | Cited By in Scopus 
Ouwehand C,de Ridder DT, Bensing, J.

A review of successful aging models: Proposing proactive coping as an important additional strategy.

Clinical Psychology Review, 2007,

Paulus, 1951 J. Paulus, Philosophy of human life, some of the conditions of a happy maturity and old age, Dialectica 5 (1951), pp. 393-401.

Pearlin and McKean Skaff, 1996 L.I. Pearlin and M. McKean Skaff, Stress and the life course: A paradigmatic alliance, The Gerontologist 36 (1996), pp. 239-247. View Record in Scopus | Cited By in Scopus

Prenda and Lachman, 2001 K.M. Prenda and M.E. Lachman, Planning for the future: A life management strategy for increasing control and life satisfaction in adulthood, Psychology and Aging 16 (2001), pp. 206-216. Abstract | Abstract + References | PDF (1039 K) | Full Text via CrossRef | View Record in Scopus | Cited By in Scopus

Rapkin and Fisher, 1992 B.D. Rapkin and K. Fisher, Framing the construct of life satisfaction in terms of older adults' personal goals, Psychology and Aging 7 (1992), pp. 138-149. Abstract | PDF (1116 K) | Full Text via CrossRef | View Record in Scopus | Cited By in Scopus

Rothermund and Brandtstädter, 2003a K. Rothermund and J. Brandtstädter, Coping with deficits and losses in later life: From compensatory action to accommodation, Psychology and Aging 18 (2003), pp. 896-905. SummaryPlus | Full Text + Links | PDF (91 K) | Full Text via CrossRef | View Record in Scopus | Cited By in Scopus

Rothermund and Brandtstädter, 2003b K. Rothermund and J. Brandtstädter, Depression in later life: Cross-sequential patterns and possible determinants, Psychology and Aging 18 (2003), pp. 80-90. Abstract | Abstract + References | PDF (90 K) | Full Text via CrossRef | View Record in Scopus | Cited By in Scopus

Rowe and Kahn, 1987 J.W. Rowe and R.L. Kahn, Human aging: Usual and successful, Science 237 (1987), pp. 143-149. View Record in Scopus / Cited By in Scopus

Rowe and Kahn, 1997 J.W. Rowe and R.L. Kahn, Successful aging, The Gerontologist 37 (1997), pp. 433-440. View Record in Scopus | Cited By in Scopus

Ryff, 1989 C.D. Ryff, Beyond Ponce de Leon and life satisfaction: New directions in quest of successful ageing, International Journal of Behavioural Development 12 (1989), pp. 35-55. Full Text via CrossRef

Schaie and Baltes, 1975 K.W. Schaie and P.B. Baltes, On sequential strategies in developmental research: Description or explanation?, Human Development 18 (1975), pp. 384-390. View Record in Scopus | Cited By in Scopus

Scheidt and Humpherys, 1999 R.J. Scheidt and D.R. Humpherys, Successful aging: What's not to like?, Journal of Applied Gerontology 18 (1999), pp. 277-283.

Schulz and Heckhausen, 1996 R. Schulz and J. Heckhausen, A life span model of successful aging, American Psychologist 51 (1996), pp. 702-714. Abstract | Abstract + References | PDF (1798 K) | Full Text via CrossRef | View Record in Scopus | Cited By in Scopus

Schwartz et al., 1999 J.E. Schwartz, J. Neale, C. Marco, S.S. Shiffman and A.A. Stone, Does trait coping exist? A momentary assessment approach to the evaluation of traits, Journal of Personality and Social Psychology 77 (1999), pp. 360-369. Abstract | Abstract + References | PDF (1084 K) | Full Text via CrossRef | View Record in Scopus | Cited By in Scopus

Smith et al., 1999 J. Smith, W. Fleeson, B. Geiselmann, R.A. Settersten and U. Kunzmann, Sources of well-being in very old age. In: P.B. Baltes and K.U. Mayer, Editors, The Berlin aging study: Aging from 70 to 100, Cambridge University Press, New York (1999), pp. 450-471.

Steverink et al., 1998 N. Steverink, S. Lindenberg and J. Ormel, Towards understanding successful ageing: Patterned change in resources and goals, Ageing and Society 18 (1998), pp. 441-467. View Record in Scopus | Cited By in Scopus

Tornstam, $1992 \mathrm{~L}$. Tornstam, The quo vadis of gerontology: On the scientific paradigm of gerontology, The Gerontologist 32 (1992), pp. 318-326. View Record in Scopus | Cited By in Scopus

Torres, $1999 \mathrm{~S}$. Torres, A culturally-relevant theoretical framework for the study of successful ageing, Ageing and Society 19 (1999), pp. 33-51. Full Text via CrossRef | View Record in Scopus | Cited By in Scopus

Torres, $2003 \mathrm{~S}$. Torres, A preliminary empirical test of a culturally-relevant theoretical framework for the study of successful aging, Journal of Cross-Cultural Gerontology 18 (2003), pp. 79-100. Full Text via CrossRef | View Record in Scopus | Cited By in Scopus

Wrosch et al., 2003 C. Wrosch, M.F. Scheier, S.C. Carver and R. Schulz, The importance of goal disengagement in adaptive self-regulation: When giving up is beneficial, Self and Identity 2 (2003), pp. 1-20. Full Text via CrossRef

Wrosch et al., 2003 C. Wrosch, M.F. Scheier, G.E. Miller, R. Schulz and C.S. Carver, Adaptive selfregulation of unattainable goals: Goal disengagement, goal reengagement, and subjective wellbeing, Personality and Social Psychology Bulletin 29 (2003), pp. 1494-1508. Full Text via CrossRef 
Ouwehand C,de Ridder DT, Bensing, J.

A review of successful aging models: Proposing proactive coping as an important additional strategy.

Clinical Psychology Review, 2007,

| View Record in Scopus | Cited By in Scopus 